\title{
Convective formation of pileus cloud near the tropopause
}

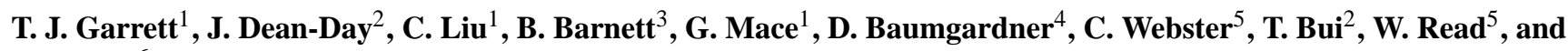 \\ P. Minnis ${ }^{6}$ \\ ${ }^{1}$ Department of Meteorology, University of Utah, Salt Lake City, Utah, USA \\ ${ }^{2}$ Atmospheric Chemistry and Dynamics Branch, NASA Ames Research Center, Moffett Field, California, USA \\ ${ }^{3}$ WB-57 Program Offices, NASA Johnson Space Center,Ellington Field, Houston, Texas, USA \\ ${ }^{4}$ Universidad Nacional Autonoma de Mexico, Mexico City, Mexico \\ ${ }^{5}$ Jet Propulsion Laboratory, 4800 Oak Grove Drive, Pasadena, California, USA \\ ${ }^{6}$ NASA Langley Research Center, Hampton, Virginia, USA
}

Received: 6 July 2005 - Published in Atmos. Chem. Phys. Discuss.: 8 September 2005

Revised: 20 December 2005 - Accepted: 15 February 2006 - Published: 19 April 2006

\begin{abstract}
Pileus clouds form where humid, vertically stratified air is mechanically displaced ahead of rising convection. This paper describes convective formation of pileus cloud in the tropopause transition layer (TTL), and explores a possible link to the formation of long-lasting cirrus at cold temperatures. The study examines in detail in-situ measurements from off the coast of Honduras during the July 2002 CRYSTAL-FACE experiment that showed an example of TTL cirrus associated with, and penetrated by, deep convection. The TTL cirrus was enriched with total water compared to its surroundings, but was composed of extremely small ice crystals with effective radii between 2 and $4 \mu \mathrm{m}$. Through gravity wave analysis, and intercomparison of measured and simulated cloud microphysics, it is argued that the TTL cirrus originated neither from convectively-forced gravity wave motions nor environmental mixing alone. Rather, it is hypothesized that a combination of these two processes was involved in which, first, a pulse of convection forced pileus cloud to form from TTL air; second, the pileus layer was punctured by the convective pulse and received larger ice crystals through interfacial mixing; third, the addition of this condensate inhibited evaporation of the original pileus ice crystals where a convectively forced gravity wave entered its warm phase; fourth, through successive pulses of convection, a sheet of TTL cirrus formed. While the general incidence and longevity of pileus cloud remains unknown, in-situ measurements, and satellite-based Microwave Limb Sounder retrievals, suggest that much of the tropical TTL is sufficiently humid to be susceptible to its formation. Where these clouds form and persist, there is potential for an irreversible repartition from water vapor to ice at cold temperatures.
\end{abstract}

\footnotetext{
Correspondence to: T. Garrett

(tgarrett@met.utah.edu)
}

\section{Introduction}

At low latitudes, the tropopause transition layer (TTL) represents the layer between approximately 14 to $18 \mathrm{~km}$ altitude through which tropospheric air enters the stratosphere (Rosenlof, 2003). It is characterized by high vertical gradients in water concentration and a local minimum in temperature.The mechanisms governing distributions of water vapor and ice in the TTL have attracted considerable interest. This is primarily because these species contribute to the planetary greenhouse effect by strongly absorbing terrestrial radiation at temperatures typically $100 \mathrm{~K}$ colder than the surface.

This paper attempts to describe a process in the TTL that has been largely overlooked, but is visibly associated with a repartition of water from vapor to ice. When clear, moist, stratified air is pushed upward above rising deep convection, it cools adiabatically. The activity of solution aerosols in the air increases, sometimes to the point that they freeze homogeneously. The newly formed ice crystals subsequently grow by the diffusion of water vapor to their surface. The process is visible as a tenuous veil that forms over the tops of convective cloud turrets. These clouds have been called pileus, from the Latin word for the felt caps that were worn by freed slaves.

The motivation for studying cloud formation of any type in the TTL is that the effects of water molecules on atmospheric processes is different in the condensed phase than it is in the gas phase. For one, condensate settles, and can dessicate air. Second, when molecular dipoles such as $\mathrm{H}_{2} \mathrm{O}$ are placed in close proximity, as they are in condensate, they respond to electromagnetic radiation by vibrating in phase, greatly amplifying the interaction with electromagnetic radiation.

In the case of pileus clouds, however, normally it would be assumed that their formation is associated only with transient effects on water vapor concentrations and radiative fluxes once the convective pressure forcing is removed, TTL air

Published by Copernicus GmbH on behalf of the European Geosciences Union. 


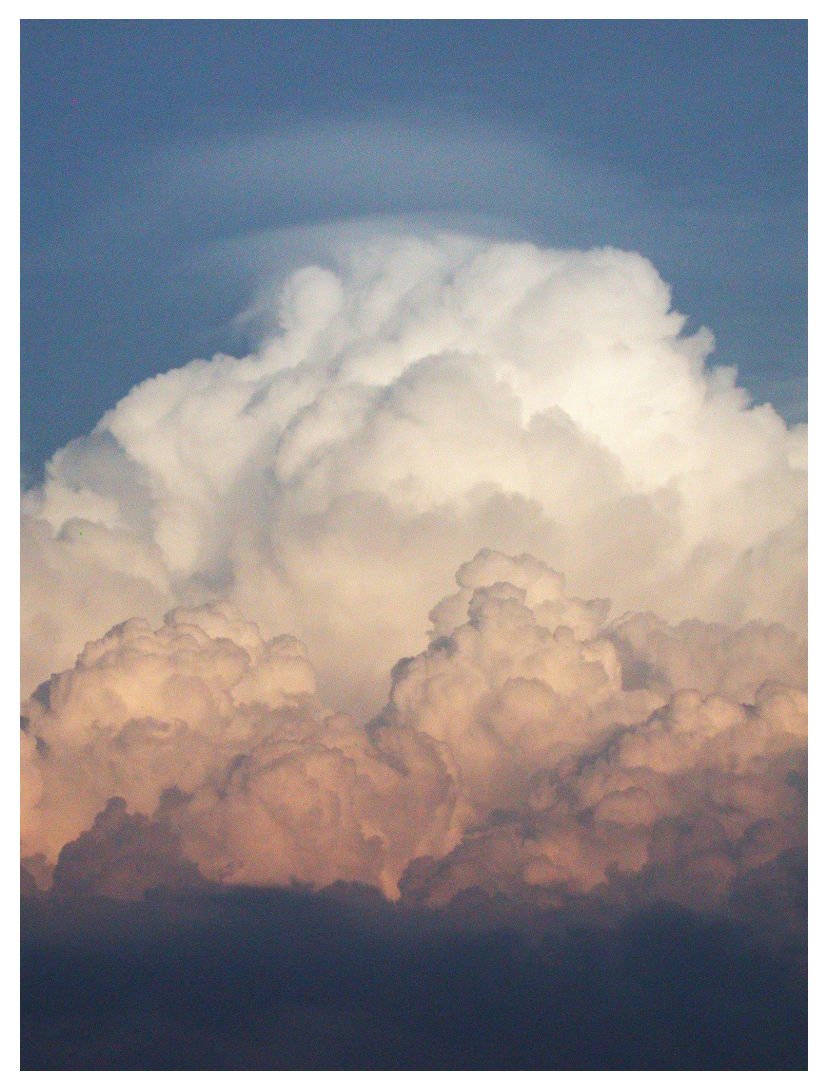

Fig. 1. Photo of pileus forming on top of deep convection over land near Darwin, Australia on 14 November 2004 at 07:05 p.m. local time.

returns to its previously clear initial atmospheric state. Here, we examine this assumption more closely using photography, in situ measurements, and numerical simulations. An argument is made that, where the TTL is initially supersaturated, or pileus is punctured and mixes with deep convection, pileus cloud may linger. If so, an irreversible repartion from vapor to condensate occurs within TTL air.

\section{Photography}

For illustration, we show two examples of pileus clouds forming near the tropopause. The first shows pileus forming in "stacked" layers above a deep convective storm that developed over land in the Tropical Western Pacific region near Darwin, Australia $\left(12^{\circ} \mathrm{S}, 130^{\circ} \mathrm{E}\right)$ (Fig. 1). At the Darwin airport, fifteen minutes after this photograph was taken, there was extensive lightning, an unusually intense surface gust front of $83 \mathrm{~km} \mathrm{~h}^{-1}$, a temperature drop of $10^{\circ} \mathrm{C}$, and the precipitation intensity reached $80 \mathrm{~mm} \mathrm{~h}^{-1}$. It is impossible to say with certainty, but the vigor of the storm is suggestive that, near the time the photograph was taken, the convective tops were near the tropopause, which local soundings indicate was located at $17.8 \mathrm{~km}$ and $186 \mathrm{~K}$. According to the ap- parent height of the convective cloud in the photograph, the convection had pushed the moist layer that formed the pileus cloud about $10 \%(2 \mathrm{~km})$ higher.

A similar example of pileus formation above deep convection has been described by Scorer (1972), based on observations in Kenya. A series of four photographs showed deep convection forming then puncturing pileus cloud. Once the convection subsided, the pileus lingered and spread. At the same time, anvil outflow from the deep convection spread as a separate cloud layer beneath the newly formed cirrus. Photographs in Fig. 2, which were taken over Louisiana at an altitude of $12 \mathrm{~km}$, appear to show a similar process. Turbulent cirrus anvil outflow spreading from deep convection was apparently accompanied by two thinner, laminar cloud layers at higher altitudes. It is possible the highest layer was preexisting. However, its horizontal extent, and the presence of wave-like features with dimensions similar to the width of the deep convective turret, suggests the layer originated as pileus cloud forced by convective uplift. The lower layer, which was more clearly pileus, enveloped the convective turret in a characteristic skullcap veil. Six minutes later, this pileus layer had been punctured by the turret, and spread laterally above the anvil. Unfortunately, no photographs were taken at later stages of development when the convection had subsided. However, at least at its edges, this lower layer appears to have survived to the point where it was evolving as TTL cirrus independent from the convection that forced it.

\section{Formation of TTL cirrus near deep convection}

The photographs show that convection can induce cirrus formation at cold temperatures and low latitudes; observations appear to indicate that sometimes overshooting deep convection can puncture a pileus cloud it forms. This is notable, because interfacial turbulent mixing is generated by shear between convective cloud and its environment (Grabowski and Clark, 1991, 1993), and humidity becomes enhanced in clear air up to several cloud radii distant (Perry and Hobbs, 1996; Lu et al., 2002). We now discuss whether a possible exchange of air between convection and its surroundings may play a role in the evolution of a pileus cloud.

While we know of no in situ observations in the TTL that were conclusively made within pileus cloud, we describe here measurements of TTL cirrus obtained from the NASA WB-57F aircraft during the July 2002 CRYSTALFACE campaign over Southern Florida and near Honduras. During CRYSTAL-FACE, measurements of ice concentrations were obtained with a Cloud and Aerosol Particle Spectrometer (CAPS) (Baumgardner et al., 2002), water vapor $w$ and total water concentrations $Q$ with the Harvard Water Probe (Weinstock et al., 1994), the optical extinction coefficient $\beta$ from a Cloud Integrating Nephelometer (CIN) (Gerber et al., 2000), total water isotopic concentrations $\mathrm{HDO}$ and $\mathrm{H}_{2} \mathrm{O}$ with the Aircraft Laser Infrared Absorption 


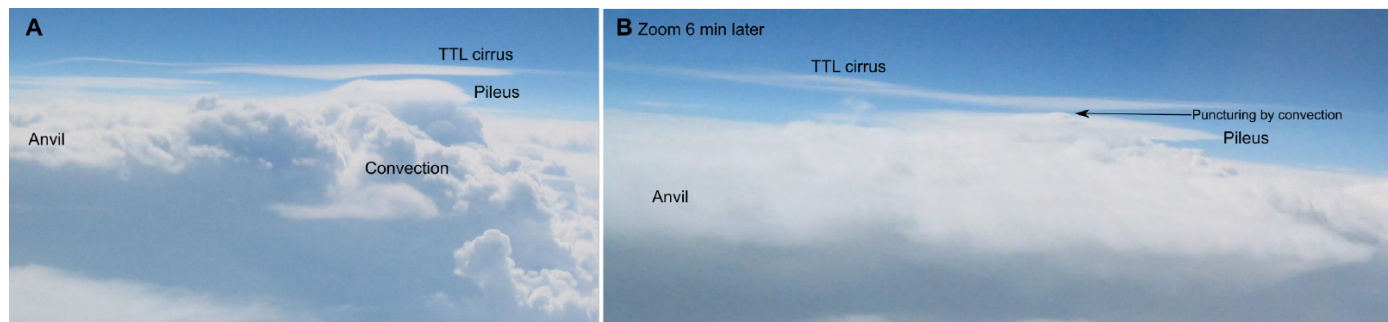

Fig. 2. Photographs of pileus and thin cirrus formation obtained at $12 \mathrm{~km}$ altitude over Louisiana on 30 April 2004 during the Mid-Latitude Cirrus Experiment (MidCiX). Photograph (B) is a closeup of the convective dome shown 6 min earlier in (A).

Spectrometer (ALIAS) (Webster et al., 1994), and temperature, pressure, and wind speed from the Meteorological Measurement System (MMS) (Scott et al., 1990).

From observations on six flights, Garrett et al. (2004) noted that cirrus had formed in the TTL directly above, but separate from anvil outflow from deep convection. In these cases, the anvil and TTL cirrus did not appear to have formed independently. Cloud boundaries established from aircraft and satellite indicated that the TTL cirrus had nearly the same horizontal extent and location as the anvil. Also, mixing ratios of nitrogen oxide (NO), potential temperature $(\theta)$, and total water in the TTL cirrus were intermediate to those observed in clear TTL air and those in anvil cirrus. Thus, it was interpreted that the formation of TTL cirrus involved a fractional contribution of air from deep convection. In the measurements, this contribution ranged up to 0.5 . In one TTL cirrus layer suitable for such analysis, measured on 21 July, spectral analysis of the temperature field showed that it contained a distinct monochromatic gravity wave signature not seen in surrounding clear air. The horizontal wavelength of this feature was $\sim 2 \mathrm{~km}-$ similar to the horizontal dimension of deep convective turrets - and its vertical amplitude was several hundred meters. The apparent combination of mixing and monochromatic wave motion led to the speculation that the TTL cirrus was forced by deep convection, but began as pileus cloud that had mixed with the convective turret.

The extent of mixing between different airmasses can be inferred from measurements of such conserved variables as enthalpy and total water. In addition, the airmass origins can be inferred from relative concentrations of isotopes of total water, since these fractionate according to their condensation temperature - a proxy for their altitude (Kuang et al., 2003; Webster and Heymsfield, 2003), and in total water, they mix linearly. According to Rayleigh distillation, atmospheric water becomes progressively lighter as an air parcel is cooled; heavier isotopes preferentially condense and precipitate. In the absence of any mixing, the depletion of HDO relative to $\mathrm{H}_{2} \mathrm{O}(\delta-\mathrm{HDO})$ would range from $-8.6 \%$ above the ocean, to $\sim-95 \%$ at the coldest tropical tropopause. Recent measurements have shown average values of $\delta$-HDO in the TTL are in fact near $-64 \%$, which argues that the origins of TTL moisture are determined by condensation processes well be- low the tropopause (Kuang et al., 2003). However, Webster and Heymsfield (2003) showed that this value is only an average, and TTL values of $\delta-\mathrm{HDO}$ are actually highly variable, ranging from -90 to $\sim 0 \%$ at horizontal scales down to $\sim 3 \mathrm{~km}$.

An illustration of a role for mixing in TTL cirrus formation is shown in Fig. 3, from a vertical descent during CRYSTALFACE by the WB-57F, first through TTL cirrus, and then followed by anvil cirrus. The aircraft flew through what, from satellite imagery, looked like a continuous anvil cloud shield, entering the TTL cirrus about $40 \mathrm{~km}$ downwind from where the anvil leading edge was located, and entering the anvil layer a further $20 \mathrm{~km}$ downwind. Values of $\delta$-HDO in the TTL cirrus were lower than those observed in anvil air beneath it, but higher than surrounding TTL air, which suggests the TTL cirrus was formed by mixing convective air into the TTL. It might be argued that the anvil cirrus and TTL cirrus were equally derived from deep convection: i.e. that the TTL cirrus formed simply from detrainment of the same convective air mass that formed the anvil; HDO was lower in the TTL cirrus simply because it had been depleted by precipitation. However, the potential temperature in the TTL cirrus was about $3 \mathrm{~K}$ colder than air immediately above and below, and about $10 \mathrm{~K}$ warmer than the anvil air. Also, total water concentrations in the TTL cirrus were intermediate to those seen in surrounding TTL air and anvil cirrus below. Because enthalpy, $\delta-\mathrm{HDO}$, and total water mix linearly, the implication is that, while the anvil formed from convective detrainment, the TTL cirrus formed through some small-scale mechanism that involved mixing of the TTL with deep convection.

A second example, showing possible interactions between deep convection and the TTL, is shown in Figs. 4 and 5 from quasi-level straight northbound flight off the coast of Honduras on 9 July 2002 at an altitude between 15 and $15.3 \mathrm{~km}$. This case is of particular interest because it shows a situation where deep convective cloud had punctured much more tenuous cirrus at the tropopause. The deep convective cloud sampled at 67350 and 67800 s UTC had $\delta-$ HDO values close to zero, indicative of air brought from the surface, with ice mixing ratio values approaching several hundreds ppmv; surrounding TTL cirrus was characterized by $\delta$-HDO values 

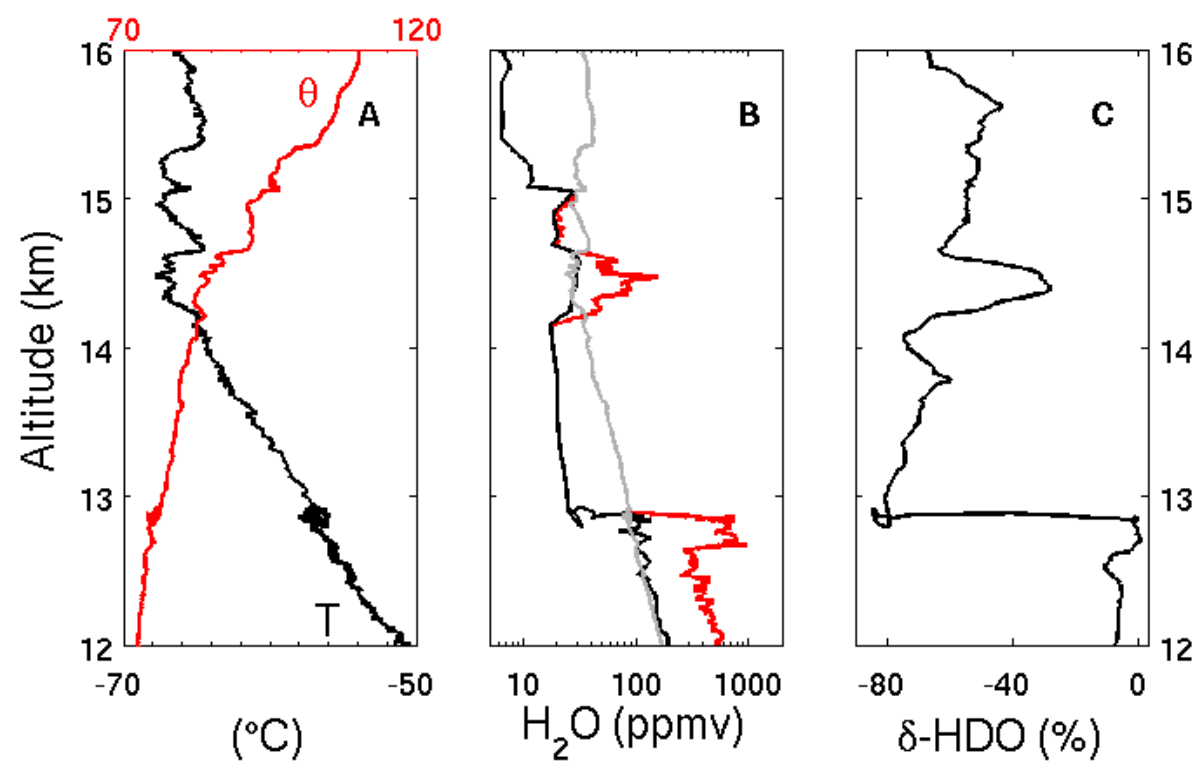

Fig. 3. Profile of (A) temperature $T$ and potential temperature $\theta,(\mathbf{B}) \mathrm{H}_{2} \mathrm{O}$ mixing ratios (measured vapour: black; saturation vapour with respect to ice: grey; total (vapour plus ice): red) and (C) $\delta$-HDO in a profile obtained on 28 July 2002 over southern Florida. Two isotopically distinct cloud layers are seen: anvil cirrus outflow from convection located below $13 \mathrm{~km}$ altitude, and a more tenuous TTL layer centered at $14.5 \mathrm{~km}$ altitude.

of $\sim-50 \%$ and ice mixing ratio values typically less than 20 ppmv. As noted by the back-seater on the aircraft at the time, the TTL cirrus was at a higher level than the anvil cirrus shield visible in Geostationary Operational Environmental Satellite (GOES)-8 imagery shown in Fig. 4.

We now explore several possibilities for the origins of the TTL cirrus shown in Fig. 5.

\subsection{Pre-existence}

First, the TTL cirrus may have formed prior to the convective event from some unrelated mechanism. Analysis of the GOES-8 imagery matched to the four nearest pixels to the flight track (Minnis et al., 1995) indicates the breadth of the cloud mass visible from space had visible optical depths $(\tau)$ sufficiently high for the cloud to act as a thermal blackbody (i.e. $\tau \gtrsim 10$ ). The satellite-derived atmospheric effective temperature $T_{\text {eff }}$ was $\sim-60^{\circ} \mathrm{C}$ where the $\mathrm{WB}-57 \mathrm{~F}$ was in TTL cirrus, and $\sim-70^{\circ} \mathrm{C}$ where it was in overshooting deep convection. For comparison, in-situ MMS measurements of temperature along the full extent of the flight leg varied about $-74 \pm 2^{\circ} \mathrm{C}$. The 4 degree difference between the retrieved and in-situ temperatures in the deep convection is symptomatic of a more general phenomenon, and its magnitude lacks satisfactory explanation (Sherwood et al., 2004). The larger, 14 degree discrepancy between in-situ and space-derived temperatures where the aircraft was in TTL cirrus indicates that the TTL layer was transparent in the infrared, and that the satellite saw primarily thermal emission from the warmer blackbody anvil layer. Outside the anvil cirrus boundaries, (denoted by A and B in Figs. 4 and 5), the TTL cirrus also terminated, and $T_{\text {eff }}$ was indicative of the lower atmosphere or surface. What is implied by these measurements is that the TTL cirrus and anvil layers overlayed one another and had nearly the same horizontal extent. Garrett et al. (2004) noted similar observations within three other similar cases during CRYSTAL-FACE, taken from flight both along and across the direction of prevailing flow. From these limited observations, it appears that TTL and anvil cirrus co-extent on 9 July may be representative of a broader phenomenon and is unlikely to be due to coincidence alone. While we lack conclusive evidence, it seems most likely that both the anvil and TTL cirrus were derived from deep convection. However, why a detached layer of TTL cirrus should spread at the same rate as the anvil beneath it is not known. We note that cooling in the TTL is enhanced by radiative equilibration to the presence of a cold blackbody anvil beneath it (Hartmann et al., 2001), and that this may encourage TTL cirrus formation and spreading.

\subsection{Detrainment}

If the TTL cirrus was associated with the observed convection, it may have been derived from the detrainment of cloudy air. If the cloud was subsequently dessicated through precipitation, a tenuous layer depleted in HDO would remain. We believe this is unlikely. Abrupt gradients in $\delta-\mathrm{HDO}$ and $Q$ were observed along the flight path between the convection and TTL cirrus. To account for these would have required that most of the ice crystal mass in the deep 


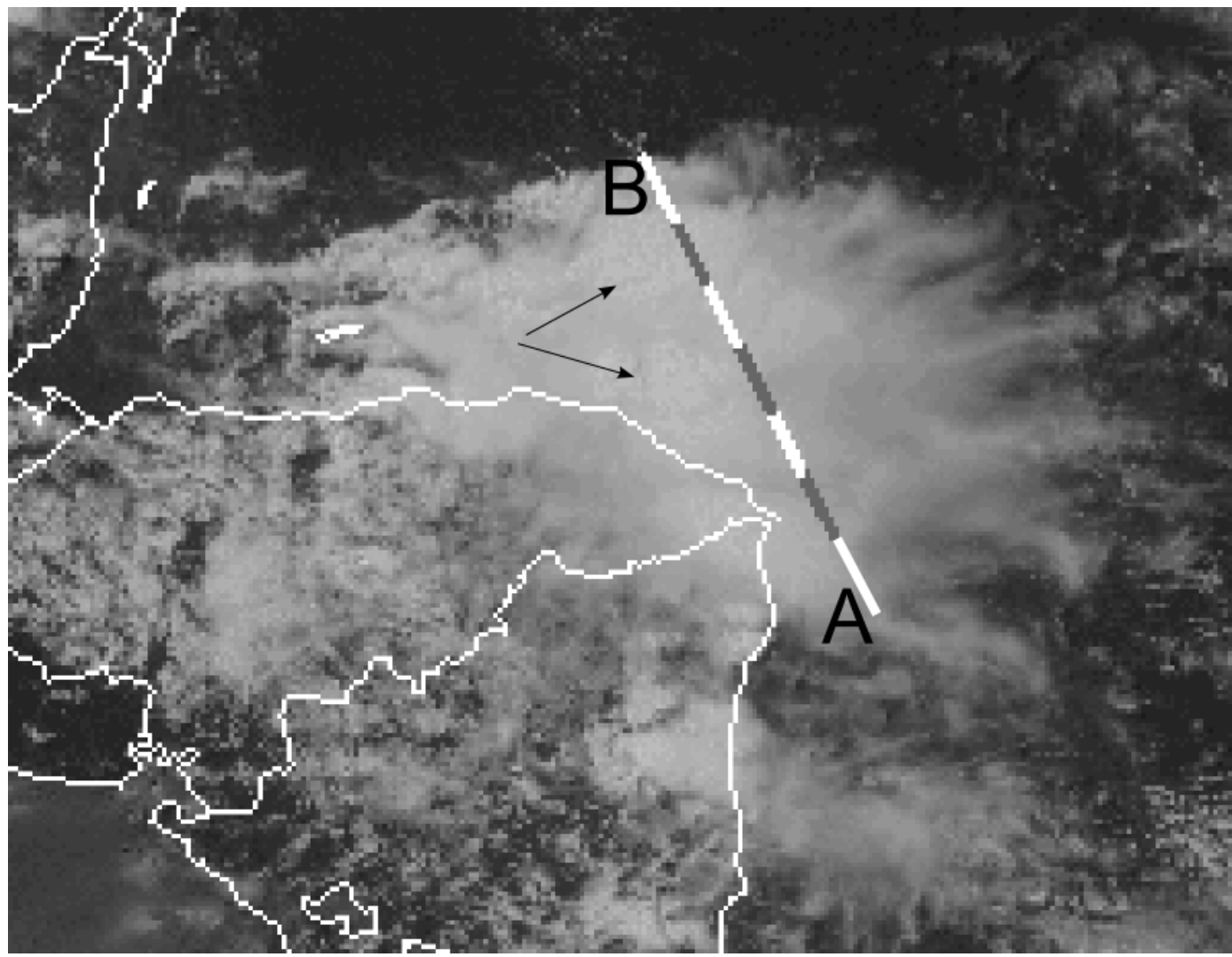

Fig. 4. WB-57F flight leg through cloudy air at approximately $15 \mathrm{~km}$ altitude off the East coast of Honduras during the CRYSTAL-FACE experiment, in 5 min segments beginning at A on 66300 s UTC 9 July 2002. Arrows point to regions of overshooting deep convection.

convection was contained in large hydrometeors that precipitated quickly once ejected into the TTL.

To evaluate the role of precipition in the formation of the TTL cirrus more closely, we derived values of the ice crystal mass and the effective radius $r_{e}$ (the ratio of the third to the second moment of the size distribution) using two techniques. The first employed size distributions from the CAPS probe. For particles between about 0.5 and $50 \mu \mathrm{m}$, the CAPS probe measures particle diameter. Larger particles $<1500 \mu \mathrm{m}$ across were imaged using an occultation technique that yields particle cross-sections. To calculate particle mass and effective radius from these data, we assumed the smaller, cloud mode particles were spheres, and reduced the cross-sections of the larger, precipitation mode particles to a circle with equivalent area, and then derived particle volume by assuming sphericity. The second approach to deriving $r_{e}$ used combined bulk-probe measurements of ice water and optical extinction from the Harvard water and CIN probe. Bulk probe measurements of $r_{e}$ are less sensitive to condensate than the CAPS probe (hence the incomplete data set in the more tenuous TTL cloud), and they do not give size-resolved information, but ostensibly they are more accurate as they are insensitive to particle morphology (Garrett et al., 2003). Roskovensky (2004) found close agreement in comparisons of bulk-probe derived $r_{e}$ with values derived from overflight of a MODIS Airborne Simulator aboard the NASA ER-2 aircraft during sampling of thin cirrus on 26 July during CRYSTAL-FACE. On 9 July, both sets of in-situ measurements showed values of $r_{e}$ between 5 and $6 \mu \mathrm{m}$ in the the deep convective cloud, of which only 0.5 to $1 \mu \mathrm{m}$ could be attributed to the presence of precipitation mode ice crystals (Fig. 5). This was because the contribution to total ice crystal mass from precipitation mode ice crystals with area-equivalent radii larger than $25 \mu \mathrm{m}$ was less than $10 \%$ and $15 \%$ in the first and second convective penetrations, respectively. The effective radius of the precipitation mode particles alone was about $30 \mu \mathrm{m}$, which corresponds to a gravitational settling rate of just $10 \mathrm{~cm} \mathrm{~s}^{-1}$. Therefore, most of the convective mass was in suspension, and the mass that wasn't settled slowly. It is therefore difficult to explain how detrainment from convection could account for the observed contrasts in $Q$ and $\delta$-HDO between the convective and TTL cirrus cloud.

\subsection{Wind shear}

Alternatively, numerical models show that strong wind shear over the top of a mid-latitude convective domes can favor 


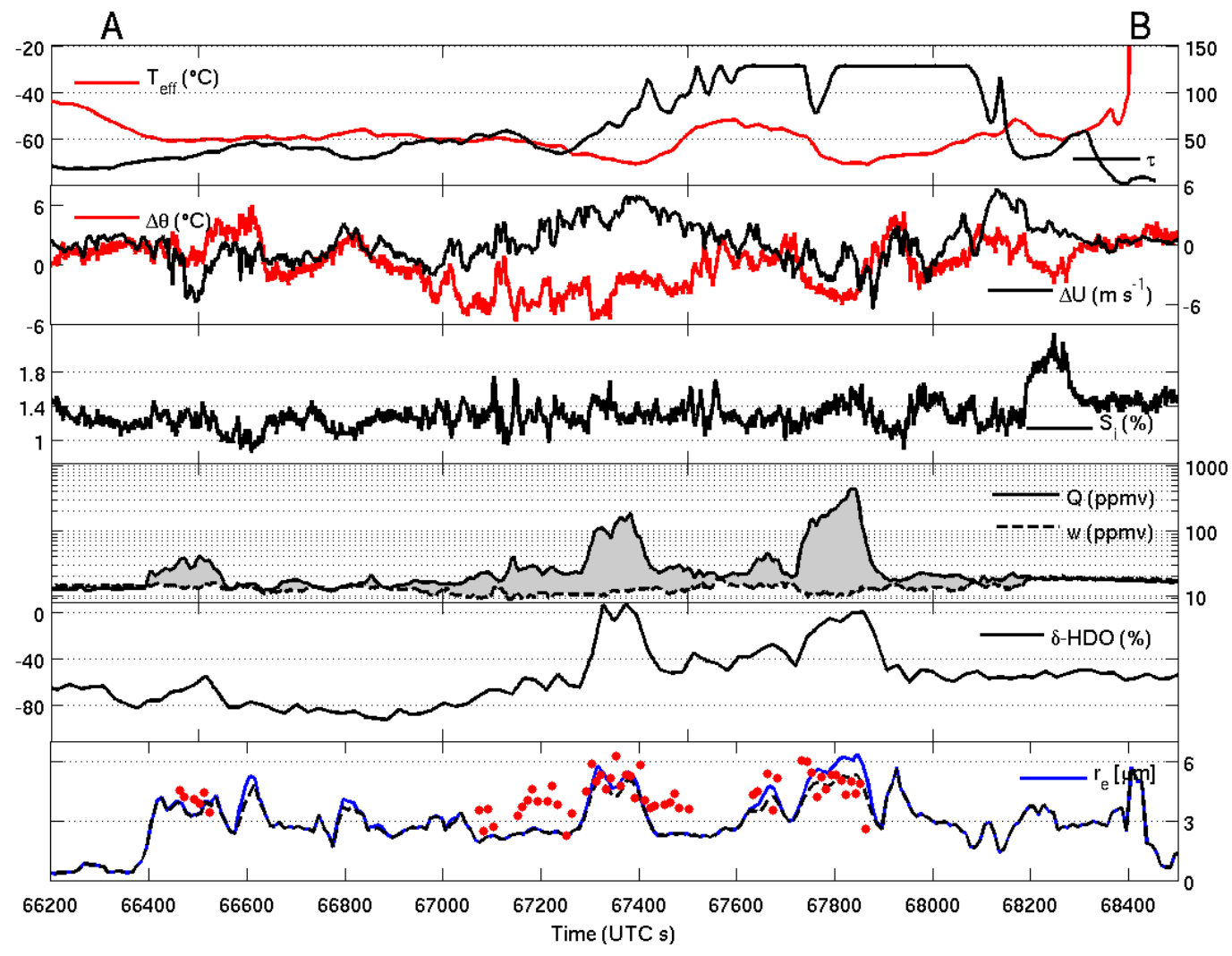

Fig. 5. In-situ and satellite retrievals corresponding to the flight leg shown in Fig. 4, and bounded by letters A and B. Measurements show, GOES-8 retrievals of cloud effective temperature $T_{\text {eff }}$ and optical depth $\tau$, in-situ perturbations to environmental potential temperature $\Delta \theta$ and zonal wind velocity $\Delta U$ from the MMS instrument, the saturation ratio with respect to ice $S_{i}$ and total $Q$ and vapor $w$ water mixing ratios from the Harvard water probe, fractionation of $\mathrm{HDO}$ relative to $\mathrm{H}_{2} \mathrm{O}, \delta-\mathrm{HDO}$, from the ALIAS probe, and ice crystal effective radius $r_{e}$ from the CAPS probe (blue line - total; dashed black line - cloud mode only), and the CIN and Harvard water probes (red dots). Shaded area shows mixing ratios of ice.

“jumping cirrus" (Fujita, 1982), or breaking gravity waves that entrain "gulps" of convective air which then spread out as thin layers of cirrus (Wang, 2003). These model results are qualitatively consistent with thin cirrus seen in multispectral satellite imagery of plumes spreading downwind of mid-latitude deep convective storm tops (Setvák et al., 2003). At tropical latitudes, Yamamoto et al. (2003) showed that, in a $1 \mathrm{~km}$ layer above the tropical temperature minimum, $R i$ is usually less than 0.5 , and sometimes less than the "critical" value of 0.25 below which shear generated turbulence is sustained, but that elsewhere the TTL is very stable. MMS profiles before and after the TTL cloud transect on 9 July indicated the cloud was embedded in a nearly isothermal environment. Combined with measurements of wind shear in aircraft profiles just prior to and following the TTL cirrus flight leg, we calculated that $R i$ ranged from $\sim 1.5$ to $\sim 11$. Also, the MMS measured kinetic eddy dissipation rate $\varepsilon$ in the TTL cirrus was just $10^{-6} \mathrm{~W} / \mathrm{kg}$. While this was ten times higher than values of $\varepsilon$ observed in surrounding clear air, it is still exceptionally low. It is unlikely that vigorous cirrus formation mechanisms were playing a role in this case.

\subsection{Gravity waves}

It has been noted previously (Potter and Holton, 1995) that deep convection can force gravity waves that propagate vertically into the stratosphere where they may induce cloud formation. Lane et al. (2001) used numerical and analytical arguments to show that gravity-waves can be produced by the vertical oscillation of convective turrets about their level of neutral buoyancy (LNB) as they move with the wind.

There is some evidence for convectively-forced gravity wave motions in the 9 July case (Fig. 5). Fluctuations in zonal wind $(\mathrm{U})$ and $\mathrm{T}$ were found in WB-57F MMS data between 67700 and $68300 \mathrm{~s}$ UTC within a layer between 15.0 and $15.3 \mathrm{~km}$. The initial encounter with a convective plume at $67800 \mathrm{~s}$ UTC was associated with a temperature drop of $\sim 3 \mathrm{~K}$. As the convective air was colder than its surroundings, the convective plume had risen above its LNB, locally squeezing isentropes upward. Two subsequent temperature drops ranged from 1.5 to $2.2 \mathrm{~K}$, but were not within dense cloud. As such, these latter fluctuations represent gravity wave motions forced by the convection, with the strongest 
within the decelerating plume itself. Nearly constant temperature during climbs before and after the TTL cirrus measurements indicate the environment was locally quasi-isothermal. The tropopause altitude $(14.9 \mathrm{~km})$ was just slightly below the aircraft track. Because gravity waves were forced within relatively stable air overlying the decelerating updraft, we conclude the WB-57F was sampling near the forcing level for the wave field. MMS time series of $U$ and $\theta$ perturbations show that gravity waves were first observed at $67000 \mathrm{~s}$ UTC, prior to entering the first convective plume at $\sim 67300$ s UTC, and again at $67800 \mathrm{~s}$ UTC, when the second updraft core was reached. A similar signature was seen in the saturation and water vapor mixing ratios. During the first encounter, only modest cooling was associated with a portion of the plume itself. Much of the wave energy appears to have dispersed in the direction of the approaching aircraft, suggesting the plume had significantly decayed. in contrast, cooling within the second updraft was much stronger, and better correlated with the total water and $\delta$-HDO time series. Since this cooling took place at the leading edge of the gravity wave field, we believe this particular updraft was forcing the observed waves that followed its penetration.

At $67930 \mathrm{~s}$ UTC, $100 \mathrm{~s}$ period (in flight time) oscillations in MMS measurements of $U$ and $\theta$ appear to be almost in phase. This suggests waves were propagating up and away from the convection, but at a frequency more typically associated with decaying waves (Dean-Day et al., 1998). Because a low-stability region was evident in the MMS temperature profile above the convection at $16 \mathrm{~km}$ altitude, wave reflection may have also altered the phase relationship between $U$ and $\theta$ from the canonical quarter-cycle often observed at lower intrinsic frequencies.

Because of the damping effect of the aircraft mass, MMS vertical winds are most responsive at shorter observed periods $(<50 \mathrm{~s})$. Since we are investigating somewhat longer periods, we instead estimate the updraft velocity of the wave from the sampling geometry, estimates of convection velocity, and linear wave theory. These calculations indicate a gravity wave of $\sim 7 \mathrm{~km}$ wavelength having an updraft velocity amplitude of $W \sim 4 \mathrm{~m} \mathrm{~s}^{-1}$, and an intrinsic frequency of $\hat{\omega}=0.015 \mathrm{~s}^{-1}$ (see Appendix A). These results are consistent with others outlined by Garrett et al. (2004), which described the dynamics of a TTL cirrus as being driven by high frequency waves with an amplitude and wavelength consistent with forcing from uplift of the TTL by a turret of deep convection. Convection produces dispersive waves covering a wide spectrum in frequency and energy. However, theoretically, "stationary-phase" solutions to an initial value problem for the temporary displacement of stratified air (Lighthill, 2001) indicate the highest frequency waves, approaching the buoyancy frequency $N$, have the largest vertical amplitude. Therefore, it is these that are most likely to produce the cooling required for cloud formation.

However, while it is quite plausible that these rapid, highamplitude gravity-wave motions could have forced cloud for- mation within clear TTL air, the magnitude of the temperature fluctuations was nonetheless too small to account for the elevated levels of $Q$ observed. The TTL cirrus was enriched in water by several tens of ppmv relative to surrounding air while adiabatic vertical displacement of a parcel at this level corresponds to apparent enrichment of just $1.6 \mathrm{ppmv} \mathrm{K}^{-1}$. Second, the TTL cirrus exhibited no apparent correlation between the magnitude of $Q$, and fluctuations in $\theta$ or $U$, which suggests the two were largely unrelated. While gravity waves may have played a role in the formation of ice mass, it was apparently minor.

\subsection{Mixing with clear TTL air}

A more likely explanation for the elevated levels of $Q$ observed is that successive pulses of deep convective cloudy air mixed ice and water into the surrounding TTL. If the surrounding air were sub-saturated, as it might be at lower altitudes, the mixing would leave a halo of high humidity around the cloud. On 9 July, however, the TTL was initially supersaturated with respect to ice, with average values of $S_{i}$ of about 1.2, so ice would be expected to linger.

To test this hypothesis, we create a simple mixing model based on the assumption that total water $Q$, temperature $T$, and ice crystal number $N_{i}$ mix linearly between cloudy air derived from convection and ambient clear air intially free of hydrometeors, i.e.,

$\zeta_{\text {mixture }}=(1-f) \zeta_{\text {clear }}+f \zeta_{\text {convection }}$

where, $\zeta$ is the mixed scalar quantity and $f$ the fractional composition of the resulting mixture derived from the convection. The mixing ratio of ice $\chi$ does not mix linearly and depends on the difference between $Q_{\text {mixture }}$ and $S_{i} w_{\text {sat }}\left(T_{\text {mixture }}\right)$, where $w_{\text {sat }}\left(T_{\text {mixture }}\right)$ is the saturation mixing ratio within the mixed air parcel. In the model, the value of $S_{i}$ in both the mixture and the convection is set to unity, $N_{i}$ in clear air is zero, and $r_{e}$ and $Q$ in the convection are $5 \mu \mathrm{m}$ and $300 \mathrm{ppmv}$, respectively. Cloud $r_{e}$ is related to $\chi$ and $\mathrm{N}$ through the cube root of their ratio. The ambient and convection temperature are set to $200 \mathrm{~K}$ and $198 \mathrm{~K}$, respectively, although, because $Q$ greatly exceeds $w_{\text {sat }}$ in the convection, this temperature difference has negligible impact on the model results.

Figure 6 shows the expected size and ice mixing ratio for mixed particles as a function of $f$ and the value of $S_{i}$ in TTL air. For example, cloud mixed into an environment with $S_{i}=0.25$ evaporates completely when dilution reaches $97 \%$, ( $f=0.03$ ), leaving a "halo" of elevated humidity around the convective core. For $S_{i}>1, \chi$ and $N_{i}$ still decrease in proportion to $1-f$, however $\chi$ decreases by a lesser amount. This is because, when ice crystals are mixed into supersaturated air, equilibrium between the vapor and ice phase demands extra condensation, and as a consequence, the particles in the mixture actually grow. 


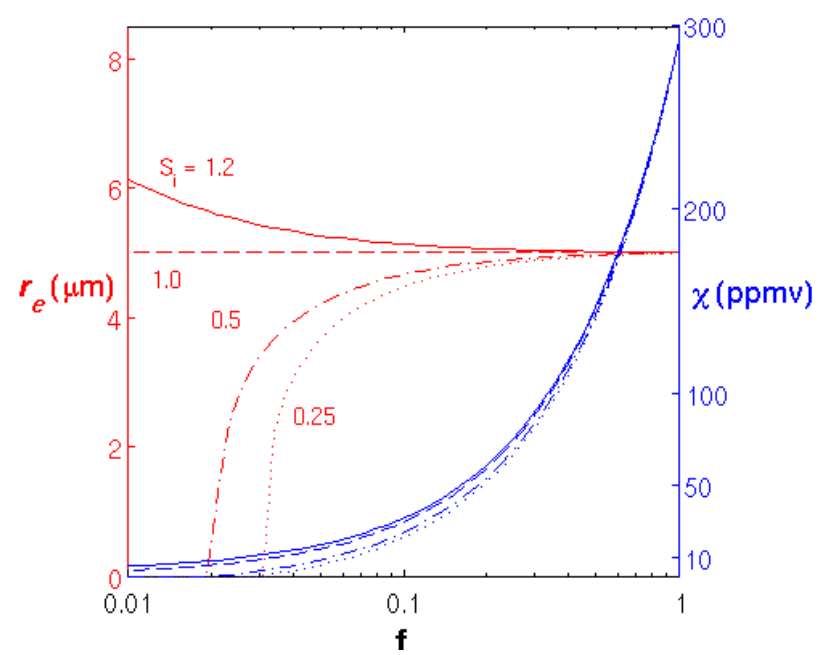

Fig. 6. Particle radius $(\mu \mathrm{m})$ (red) and ice water mixing ratio (ppmv) (blue) for a hypothetical mixing scenario between the convective cloud shown in Fig. 5 and ambient TTL air, for values of clear air TTL $S_{i}$ shown.

These model results are in partial disagreement with the observations shown in Fig. 5. If mixing were the dominant mechanism accounting for the presence of the TTL cirrus, measurements of $\chi$ in the TTL cirrus layer should imply that $f$ was less than 0.1 . In this case, the model indicates the expected value of $r_{e}$ in the TTL cirrus should be about $0.5 \mu \mathrm{m}$ higher than in the convective plume. However, two sets of in-situ observations showed values of $r_{e}$ in the TTL cirrus that were up to twice as small as those in the convection, with sizes ranging from just 2 to $4 \mu \mathrm{m}$. Arguably, this inconsistency could be ascribed to the removal of precipitation mode particles through gravitational settling, a process that was not included in the mixing model. However, as described in Sect. 3.2 the precipitation particles measured by the CAPS probe in the convection were too small to have settled out rapidly. Moreover, the precipitation particles contributed less than $1 \mu \mathrm{m}$ to the total value that was derived for $r_{e}$ in the sampled convection (Fig. 5). Therefore, even if these particles had settled rapidly, the reduction to $r_{e}$ would still have been less than that observed.

Thus, mixing between deep convection and initially clear supersaturated TTL air satisfactorily accounts for the observed ice water mixing ratios in the TTL cirrus. However, it does not account for the ice crystal sizes that were observed.

\subsection{Mixing with TTL pileus cloud}

A final explanation considered for the observations is a modification to the aforementioned mixing and gravity wave hypotheses. While mixing occurred between the convective plume and TTL air, the TTL air was not initially clear. Rather, because the TTL was initially supersaturated, a pileus cloud formed easily ahead of the rising pulse of deep convec-

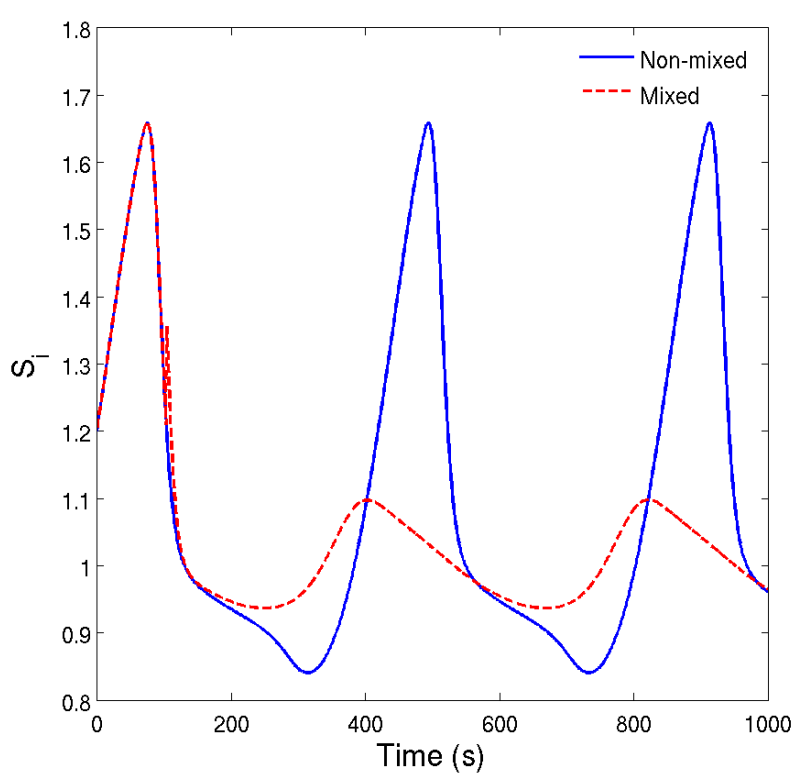

Fig. 7. Simulations of $S_{i}$ in a simulated non-dispersive gravity wave for two scenarios: (blue) pileus cloud forms, and then reforms in successive pulses of a gravity wave, and (red) the pileus cloud forms, then mixes with a deep convective plume. Mixing occurs at $100 \mathrm{~s}$.

tion. The more energetic and faster moving convection punctured the TTL cloud it formed, and mixed in convective ice mass. Interfacial mixing occured between the deep convection and ambient air throughout its trajectory, but only where it passed through initially supersaturated layers of clear air did both pileus cloud form, and mixed convective ice crystals avoid evaporation. Through successive pulses of convection and mixing, TTL cirrus was formed with the microphysical and gravity wave characteristics shown in Fig. 5 .

To test this hypothesis requires simulation of pileus dynamics and microphysics. We are aware of no detailed description of the dynamics of pileus formation. However, as a guide, dimensional analysis suggests that, from a balance between kinetic and potential energy, stratified isentropes are pushed upward by $\delta z \sim W / N$, where $N$ is the buoyancy frequency of the TTL and $W$ the vertical velocity of the convection. Thus, deep convection adiabatically cools the air it displaces by

$\delta T \sim \frac{g W}{c_{p} N}$

where $g$ is gravity, and $c_{p}$ the heat capacity of dry air. Values of $W$ in deep convection commonly reach $\sim 10 \mathrm{~m} \mathrm{~s}^{-1}$. However, above the base of the TTL, overshooting turrets decelerate, so $W$ should be somewhat smaller. As a guide, we assume the described gravity waves around the convection, with a vertical velocity amplitude of $4 \mathrm{~m} \mathrm{~s}^{-1}$, and a frequency of $0.015 \mathrm{~s}^{-1}$, were representative of the initial forcing of the pileus cloud. 

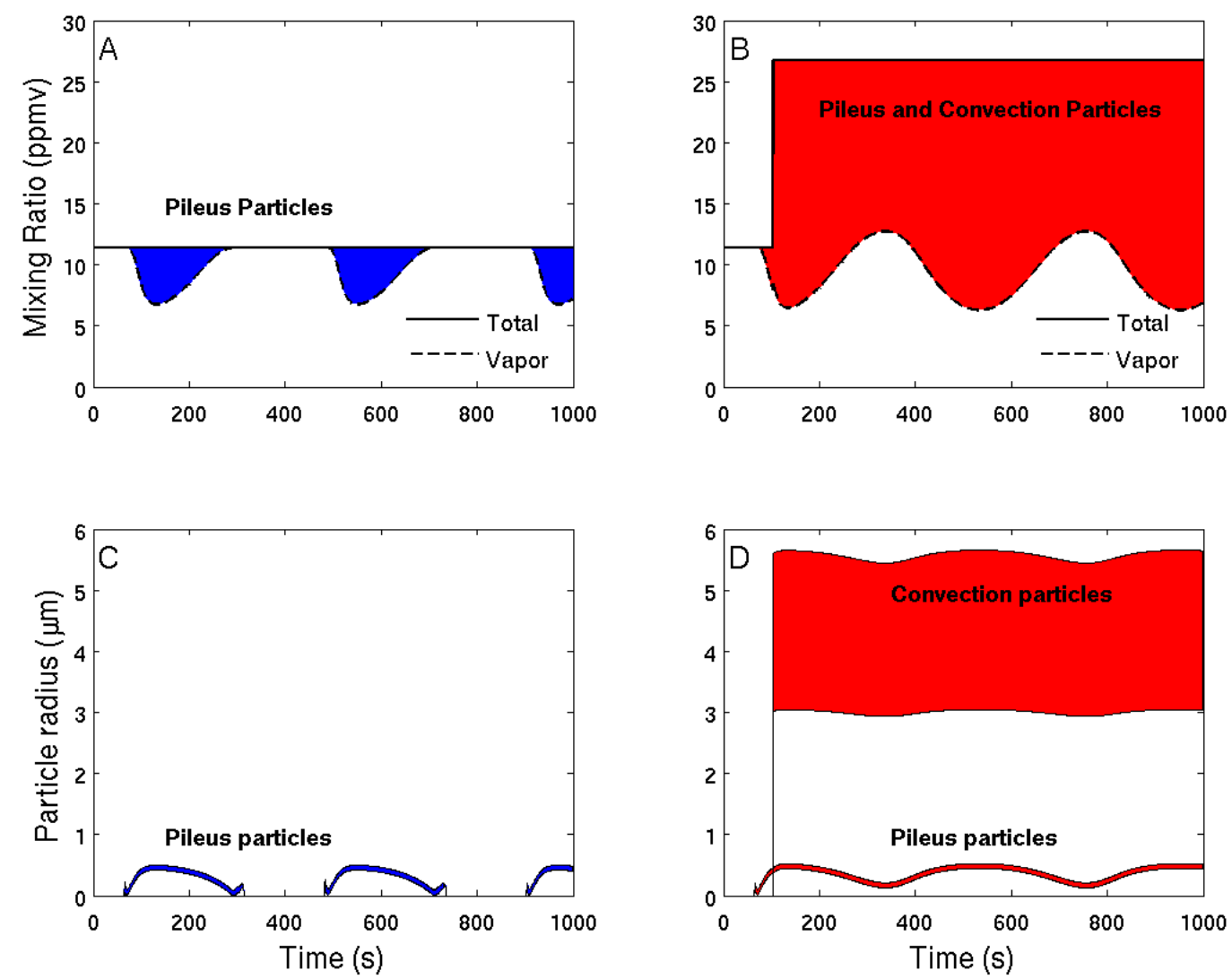

Fig. 8. As in Fig. 7 for non-mixed (A) and (C) and mixed (B) and (D) scenarios. (A) and (B) represent simulations of $w$ (dashed line), $Q$ (solid line), and $\chi$ (shaded area), and (C) and (D) represent simulations of particle radius (shaded area indicating bounds of one standard deviation away from the mean).

An estimate of the cooling forced by the displacement is of order several degrees Eq. (1). Condensate forms if this cooling is sufficient to raise the saturation ratio with respect to ice $S_{i}$ to approximately 1.6 (Koop et al., 2000; Baker and Baker, 2004). Above this level, the amount of condensate that forms is determined by the Clausius-Clapeyron relation. Our estimates of the controlling dynamics are used to force a microphysical parcel model (Appendix B), which includes homogeneous freezing of solution aerosol, ice crystal diffusional growth, and mixing. Based on the microphysical measurements in the TTL cirrus shown in Fig. 5, the parcel model is intialized to values of $S_{i}$ and $T$ of 1.2 and $198 \mathrm{~K}$, respectively. Convective air is assumed to be $3 \mathrm{~K}$ colder than its surroundings, with an ice mixing ratio of $150 \mathrm{ppmv}$ and values for $r_{e}$ of $5 \mu \mathrm{m}$.

Two cloud formation scenarios are considered. In the first, a pileus cloud forms due to convective uplift. The pileus cloud stays separate from the convection and does not mix (i.e. $f=0$ ). In the second scenario, after the pileus cloud forms, it is punctured by water-laden deep convection, and the two clouds mix. This is parameterized with a value of $f=0.1$ to be approximately consistent with the apparent wa- ter enrichment of TTL air shown in Fig. 5. In both simulations (Fig. 7), cloud forms when $S_{i}$ reaches about 1.65, following which it responds to gravity wave temperature oscillations, and water vapor diffusional growth to nucleated ice crystals. In the warm phase of the simulated gravity wave, both the mixed and non-mixed parcels become sub-saturated. However, the subsaturation is least in the parcel that had been exposed to mixing with deep convection. Through repeated wave cycles, the cloud formation process is repeated in the non-mixed parcel, but in the mixed parcel, condensation on pre-existing ice crystals inhibits the high values of $S_{i}$ required for new nucleation. In reality, new cloud formation would probably be restricted to the initial impulse in either case, due to the dispersive nature of the wave, which would dampen vertical displacement in subsequent cycles. Figure 8 shows the simulated microphysics for the mixed and nonmixed scenarios. Because the cooling was rate was exceptionally rapid, all available aerosol in the model froze, yielding an ice crystal concentration of $1263 \mathrm{~cm}^{-3}$. Kärcher and Lohmann (2002) describe similarly high concentrations for the vertical velocities we modeled. 5 ppmv of ice water condensed out at the apex of the wave and the simulated pileus 


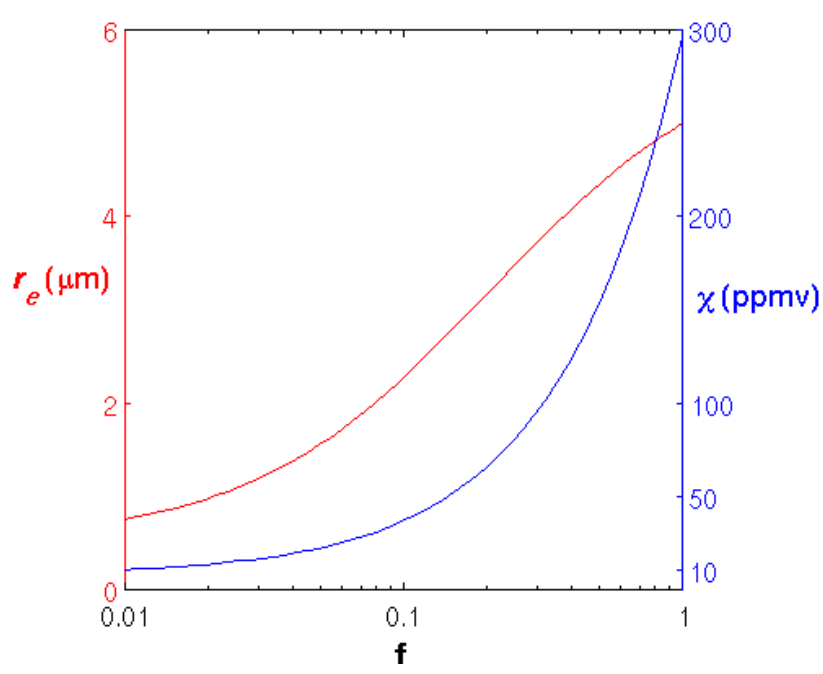

Fig. 9. As in Fig. 6, except convective air is mixed in fractional quantity $f$ into pileus cloud with $\chi=5 \mathrm{ppmv}$ and $r_{e}=0.5 \mu \mathrm{m}$.

ice crystals grew to just $\sim 0.5 \mu \mathrm{m}$ radius. These ice crystals sizes are surprisingly small, but reflect the assumed TTL aerosol concentration and the high calculated value for $\hat{\omega}$; if the aerosol concentration were lower, the ice crystals would be larger in proportion to the cube root of the concentration difference; added simulations (not shown) indicated that for $r_{e}$ to be closer to values measured in the deep convection, $\hat{\omega}$ would need to be one hundred times slower.

In the non-mixed scenario (Figs. 8a and c), where the air parcel enters the warm phase of the gravity wave, it becomes sub-saturated, and the pileus ice crystals sublimate entirely. The cloud formation process is repeated in subsequent cycles. In the mixed scenario, where convective cloud is mixed in to the pileus layer (Figs. 8b and d), the pileus layer does not entirely evaporate. This is because, as deep convection mixes with its surroundings, it contributes not just the water vapor contained in cold dry air (as suggested by Sherwood and Dessler, 2000) but water from small ice crystals as well. Because these particles sublimate along with the original pileus ice crystals in the sub-saturated portion of the wave, they provide a reservoir of water vapor that limits the full extent of sublimation in the newly formed wave cloud. The cloudy air mass that is derived from TTL air is only ever partially sublimated (Fig. 8d), and the cloud is sustained over repeated wave cycles.

In Fig. 8d, the combined effective radius of the modeled pileus and convection ice crystals was $2 \mu \mathrm{m}$, which is in reasonably good agreement with the CAPS observations in the TTL cirrus shown in Fig. 5. While still speculative, of the various hypotheses discussed for TTL cirrus formation on 9 July, it appears that the scenario of deep convective air mixing with pileus cloud is most consistent with the measurements. It accounts for both the observed TTL condensate mixing ratios $\chi$, and the observation that the TTL ice crystal (a)

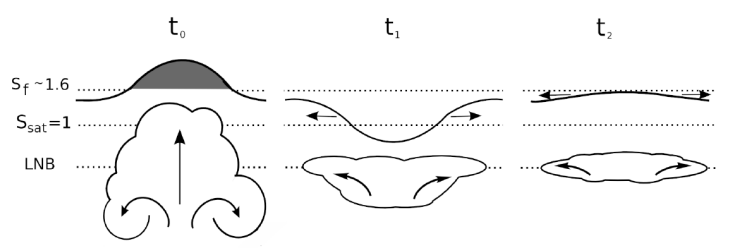

(b)

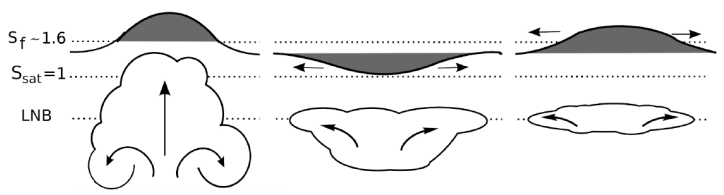

(c)

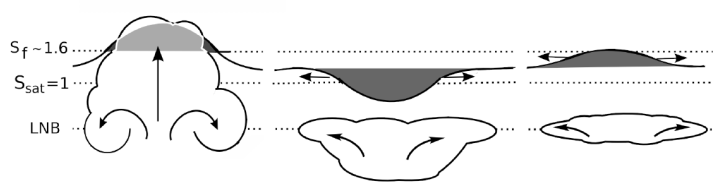

Fig. 10. A schematic diagram showing three scenarios for the hypothesized formation of pileus cloud by convection, and the subsequent evolution of the forced gravity wave. See discussion in text.

effective radius was smaller than in nearby convective air. In essence, neither mixing nor rapid gravity wave motion alone can explain the measurements; it is the combination that is required. What the parcel model does not reproduce well, however, is the observed equilibrium values for $S_{i}$ of approximately 1.2 (Fig. 7). Why $S_{i}$ should be greater than unity is unknown, and it suggests that some important physics is likely absent from our simulations. Forcing our simple mixing model to values of $S_{i}=1.2$ in the deep convective plume and surrounding TTL cirrus yields results that are similar to those derived from the parcel model (compare Figs. 8 and 9). For example, if $f<0.1$, as suggested from measurements of $\chi$ in the TTL cirrus, the corresponding values of $r_{e}$ are smaller than $2.5 \mu \mathrm{m}$, which is in close agreement with the parcel model and the measurements.

\subsection{Conceptual model}

Based on these analyses, we show in Fig. 10 a schematic of three possible scenarios by which we suspect pileus clouds might form and evolve. In the first, (Fig. 10a) an initially flat isentropic surface has a value of $S_{i}$ greater than unity $\left(S_{\text {sat }}\right)$ but below its homogeneous freezing point $S_{f}$, were it to be lifted adiabatically. Vertical perturbation of the surface by rising deep convection causes a cloud to form above the point where it reaches $S_{f}$. Once the deep convection subsides to its LNB, the isentropic surfaces are left to oscillate about their initial position. In the warm phase of the wave, the cloud evaporates where it dips below $S_{\text {sat }}$. The cloud does not reform because the wave energy propagates, diminishing the wave amplitude in subsequent cycles. 


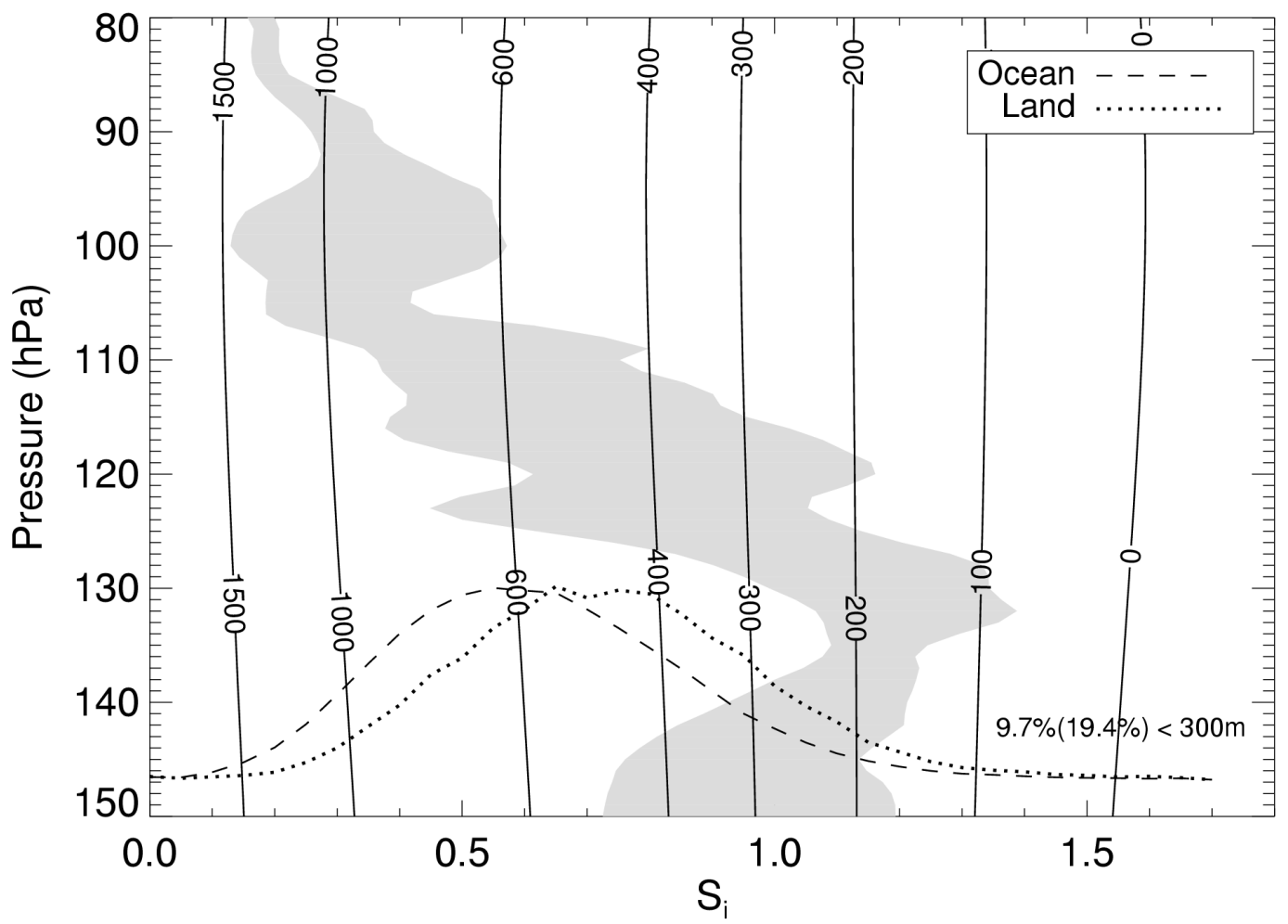

Fig. 11. Frequency distributions of $S_{i}$ in the tropical TTL at $146 \mathrm{hPa}$ retrieved between $20^{\circ} \mathrm{S}$ and $20^{\circ} \mathrm{N}$ using Version $7.02 \mathrm{Microwave}$ Limb Sounder (MLS) measurements aboard the UARS satellite (dashed - ocean; dotted - land), and in situ profiles from two flights off Honduras flown during the July 2002 CRYSTAL-FACE project (shaded area), shown as a function of the vertical pressure co-ordinate. Verticallyaligned contours represent the estimated isentropic lifting (in meters) required to initiate homogeneous freezing of haze aerosol in an air mass with the given pressure and $S_{i}$.

A second possibility (Fig. 10b), however, is that the newly formed pileus cloud never evaporates. While the wave warms, it never warms sufficiently to dip below $S_{\text {sat }}$, and hence evaporate the cloud. In this case, the newly formed cirrus will be enriched in water relative to its environment only in proportion to displacement from its equilibrium level (about several ppmv per degree depending on the temperature). Third (Fig. 10c), once the pileus cloud forms, it is punctured by the convective turret that formed it. The turret, being turbulent, mixes with the more laminar pileus cloud. Ice crystals are exchanged at their interface. Sufficient ice is donated to the pileus cloud to enable it to survive the warm phase of the ensuing oscillations, even where it dips below the level that would normally be associated with $S_{\text {sat }}$ in the absence of mixing. It is this scenario that we believe best explains the physical characteristics of the TTL cirrus shown in Fig. 5. Not shown is the possibility of pileus formation from isotherms that are initially sub-saturated. This would require considerable lifting and cooling. Also, the cloud would more likely be ephemeral, as it would almost certainly evaporate in the warm phase of the wave. Note, also, that this diagram illustrates only individual pulses of convective thermals and pileus, and not rather a continued sequence of convective impulses that would blend together to form a more continuous sheet of TTL cirrus. An analogous situation is one where a series of convective bubbles reaching the tropopause relax to their LNB to form continuous laminar anvil cloud.

\section{Susceptibility for pileus formation in the tropical TTL}

While it is evident from Fig. 1 that pileus clouds can form in the TTL, it remains unknown how often the TTL might be susceptible to pileus formation above convection. The likelihood of pileus formation at any location depends on three factors: the stratification of the TTL, the velocity of the convective uplift, and foremost, the humidity - higher values of $S_{i}$ require less lifting by convection to initiate ice crystal nucleation. In the tropics, at least, regions of TTL cirrus are highly correlated with $S_{i}$, and are most common in regions where deep convection is active (Sandor et al., 2000; Dessler and Yang, 2003; Wu et al., 2005). While we have no evidence to demonstrate these TTL cirrus originated during convective lifting, it should be considered a possibility. To illustrate, Fig. 11 shows Microwave Limb Sounder (MLS) measurements at $146 \mathrm{hPa}$ obtained during 1992 aboard the Upper Atmosphere Research Satellite (UARS) (Read et al., 2004). Superimposed on these curves is the amount of 
isentropic lifting that would be required to cool air to the point where, according to the Koop et al. (2000) formulation, haze aerosols would be expected to freeze homogeneously. For air that is initially saturated with respect to ice, the required lifting is more than about $300 \mathrm{~m}$, independent of altitude. To produce such uplift above deep convection, assuming a balance between kinetic and potential energy, $W \sim N \delta z$, implying required convective updraft velocities $>4 \mathrm{~m} \mathrm{~s}^{-1}$. Such values can reasonably be expected from convection that is above its LNB and decelerating into the TTL. Assuming $300 \mathrm{~m}$ lifting, the MLS data imply that $\sim 20 \%$ (10\%) of land (ocean) air at $146 \mathrm{hPa}$ could be expected to form pileus cloud over deep convection.

This estimate of susceptibility of the TTL to pileus formation must be considered with caution given that the uncertainty in MLS calculations of $S_{i}$ at $146 \mathrm{hPa}$ is approximately $30 \%$. Jensen et al. (1999) argued that there may be compensating errors involved in $146 \mathrm{hPa}$ MLS $S_{i}$ distributions. Random errors in measurements of temperature and $\mathrm{H}_{2} \mathrm{O}$ artifically broaden the distributions; however, the true distribution may be in fact broad because MLS values of $S_{i}$ represent an average over a vertical depth of $\sim 4 \mathrm{~km}$, whereas high humidity layers are often thinner (and presumably more common). Also high resolution aircraft measurements from CRYSTAL-FACE taken off Honduras and Costa Rica show air mostly supersaturated into the middle TTL (Fig. 11). A survey of humidity measurements from 40 ER-2 flights between approximately $10^{\circ} \mathrm{N}$ and $10^{\circ} \mathrm{S}$ (Jensen et al., 2001) showed that it was typical for air to be near supersaturation at some level between 15 and $19 \mathrm{~km}$, and in 10 -s resolution data from within $100 \mathrm{~m}$ of the tropopause to be supersaturated $30 \%$ of the time. Most recently, supersaturated TTL air has been noted in aircraft data from near Costa Rica with peak values for $S_{i}$ of 2.3 (Jensen et al., 2005).

\section{Conclusions}

The relevance of the formation of pileus cloud to how phases of water are partitioned in the TTL depends in large part on their longevity. Ordinarily it would be expected that pileus cloud could exist only in the phase of the gravity wave where $S_{i}>1$. Once the potential energy associated with the vertical displacement of the initial impulse had dispersed, the cloud would disappear. What we have argued here is that, under some situations, pileus will linger even after the convective impulse has ceased. Overshooting deep convective clouds may be dry compared to their warmer surroundings, but they are also laden with water in the form of small ice crystals: in fact, without numerous small crystals, their tops would likely not have such sharp edges or be so clearly visible. Because convection is turbulent, it necessarily mixes into its surroundings both ice crystals and water vapor. If the environment is sub-saturated, the ice quickly evaporates where we normally interpret the edge of the cloud to exist, leaving behind a halo of humid air. If the environment is supersaturated, however, it is probable that uplift ahead of the convection will be sufficient to initiate condensation. Where this pileus cloud is punctured by the faster moving convective turret, ice crystals are mixed from the convection into a cloudy atmosphere and therefore they do not completely evaporate. In fact, as described by our parcel model simulations, these ice crystals can act as a reservoir of water vapor that inhibits deep subsaturation in the warm phase of ensuing buoyancy oscillations. Consequently, the original condensation associated with the pileus cloud never fully evaporates, even once the responsible convective pressure perturbation has subsided. The result is that a repartion from water vapor to ice occurs within the fraction of the mixed air that was derived from the previously clear TTL.

In examination of the origins of a TTL cirrus layer formed off the coast of Honduras, it was this mechanism, of several that were considered, that appeared most consistent with the observations. While the ultimate fate of the TTL cirrus ice crystals in this case was unknown, other observations of TTL cirrus associated with deep convection suggest the clouds can be relatively long-lived. For example, a study of the evolution of a TTL cirrus layer above an anvil during CRYSTAL-FACE showed that the TTL cloud properties were stable, even while the anvil beneath it dissipated (Garrett et al., 2005). The longevity may have been partly because the ice crystals were small and in a supersaturated environment, such that they were unlikely to precipitate or evaporate - measurements of the TTL cirrus ice crystals indicated they were only several micrometers in radius, in which case gravitational settling was only several tens of meters per day. Also, it has been suggested by Hartmann et al. (2001), and demonstrated by Garrett et al. (2005), that TTL cirrus cools when a cold anvil layer is present below, which should sustain condensation. However, Comstock et al. (2002) had noted TTL cirrus in the Tropical Western Pacific that persisted for days following a convective event, even after the associated anvil had dissipated.

The results described here suggest a hypothesis in which, by forming pileus cloud in cold, humid environments, convection plays a lasting role in how water and ice are partitioned at cold temperatures. The redistribution is due to small-scale laminar and turbulent processes at altitudes well above the convective level of neutral buoyancy where anvil cirrus is normally found. While we provide photographic evidence that pileus clouds form at high altitudes and become TTL cirrus, we know of no in-situ measurements that are conclusively within the pileus clouds themselves. Hence, while plausible, the hypothesis remains speculative. Future space-borne measurements of the TTL using lidar and radar should help show where and how often thin cirrus layers are present above deep convection. Detailed cloud resolving model simulations might show how these clouds evolve, and quantify their potential influence to global fields of vapor and radiation near the tropopause. 


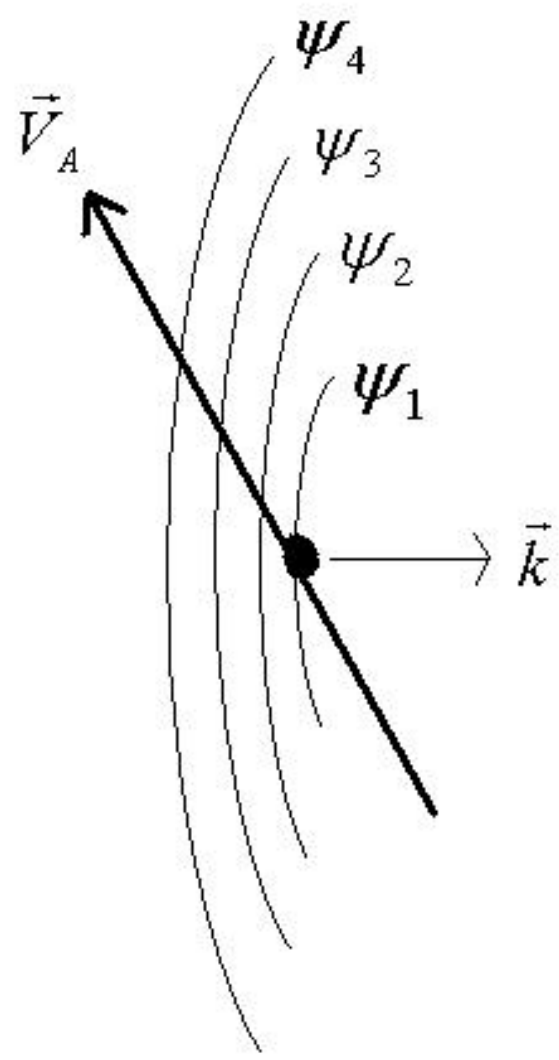

Fig. A1. Parabolic pattern formed by gravity waves generated by a convective source. Viewed from above, the updraft forcing the wave field is indicated by a black dot; two-dimensional curves of constant phase $\psi$ are shown to intersect and lie upstream from the convection. $V_{A}$ indicates aircraft velocity along the ground-based track (bold line); the wave vector $\boldsymbol{k}$ is shown as the axis of the parabolic phase curves at time $t$.

\section{Appendix A}

\section{Wave sampling}

As viewed in the horizontal plane, gravity waves generated by a convective updraft will form a steady-state, parabolicshaped field of constant phase curves, upstream from the energy source (Fig. A1). In time, each of the parabolic curves tracks the horizontal movement of the underlying convection, orienting its axis along the horizontal wind vector at the altitude of wave forcing. Here, the wave vector $\boldsymbol{k}$ is defined to lie parallel to the mean wind, but by convention must have a positive eastward component.

In general, the complex geometry of a gravity wave field can only be fully determined by means of three-dimensional, non-hydrostatic, time-dependent mesoscale models. However, one can approximately describe the pattern formed during an in-situ encounter with a wave field within a limited ge-

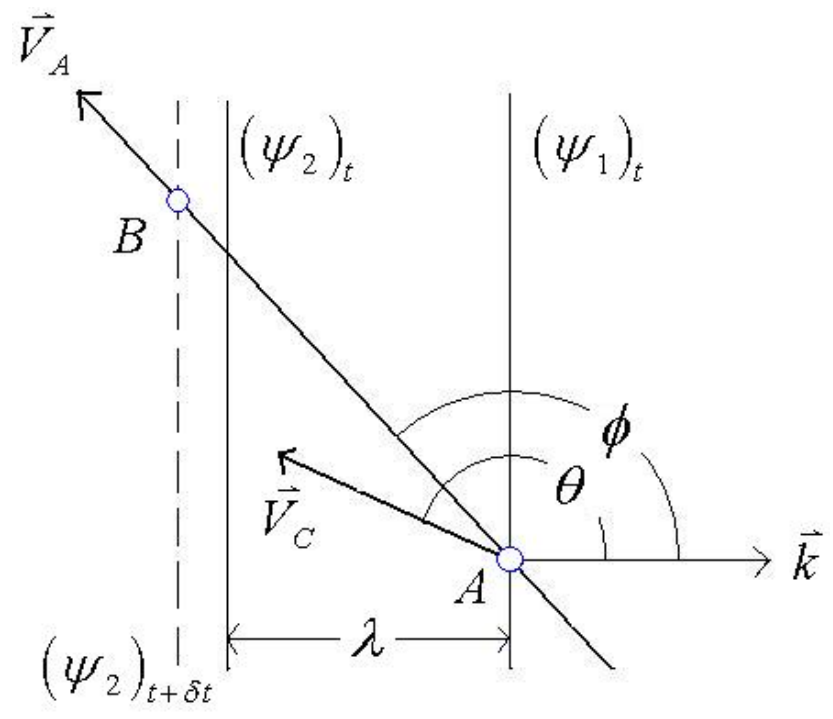

Fig. A2. Geometry of wave sampling, as viewed from above aircraft flight track. $\psi_{1}$ and $\psi_{2}$ are phase lines of a monochromatic gravity wave sampled at times $t_{1}$ (solid) and $t_{2}$ (dashed), respectively. Points $A$ and $B$ show the position of the aircraft during consecutive wave samples. Distance between phase lines equals the wavelength $\lambda$, and the wave vector $\boldsymbol{k}$ is shown orthogonal to the phase lines. $V_{A}$ and $V_{c}$ are aircraft and convection velocities with respect to earth. $\phi$ and $\theta$ are angles between the wave vector and either the aircraft track or convection velocity vector, respectively.

ographical area. If the observed wave periods are relatively constant while sampling along a quasi-level altitude, local parabolic curvature may be neglected, and lines of constant phase may be assumed.

Figure A2 depicts horizontal sampling of a single, monochromatic gravity wave forced by a convective updraft and moving at the velocity of the underlying air column. The sampling aircraft encounters a wave with phase $\psi_{1}$ at point $A$. After a time interval $\delta t$, the next wave is encountered at the same phase (i.e., $\psi_{2}=\psi_{1}+2 \pi$ ) at point $B$.

A system of equations is used to determine wavelength $\lambda$ and phase speed $c$ from the apparent wavelength $\lambda_{m}$ and period $\delta t$ derived from aircraft measurements:

$\lambda_{m}=V_{A} \delta t$

$c=V_{c} \cos \theta$

$\lambda=\left|\lambda_{m} \cos \phi-c \delta t\right|$

where, $\theta$ and $\phi$ are the angles between the wave vector and either the convection velocity $V_{c}$ or aircraft velocity $V_{A}$, respectively.

For the waveencounter of 9 July 2002 (Fig. 5), we assume the wave is forced by convection at or just below the flight altitude. Here, the wavevector $k$ is aligned with the mean 
wind $\left(\bar{U}=11 \mathrm{~m} \mathrm{~s}^{-1}, \bar{V}=0 \mathrm{~m} \mathrm{~s}^{-1}\right)$ at the WB-57 altitude. In this circumstance, intrinsic frequency $\hat{\omega}$ is defined as,

$\hat{\omega}=\frac{2 \pi}{\lambda}(c-\bar{U})$

On this day, the NASA ER-2 flew in stacked formation with the WB-57F over the same flight track, releasing a dropwindsonde approximately $250 \mathrm{~km}$ south-southeast of the convective cell, and less than $30 \mathrm{~min}$ prior to sampling of the wave by the WB-57F. Assuming the wave fieldtravels with the convection that forces it, we present solutions for $\lambda, c$, and $\hat{\omega}$ based on the convection velocity $V_{c}$ from the sonde wind data.

The first method uses the pressure-weighted mean wind, computed from the ocean surface $(1006 \mathrm{hPa})$ up to the tropopause at $\sim 132 \mathrm{hPa}$. Calculations yield $V_{c}=6.1 \mathrm{~m} \mathrm{~s}^{-1}$ from $104^{\circ}$. Here, the wave and convection velocity vectors are separated by $\theta=166^{\circ}$, resulting in $c=-5.9 \mathrm{~m} \mathrm{~s}^{-1}$. From this, $\lambda=7.2 \mathrm{~km}$ and $\hat{\omega}=0.0148 \mathrm{~s}^{-1}$.

Alternately, the steering wind at $700 \mathrm{hPa}$ may be used. Here, $V_{c}=6.4 \mathrm{~m} \mathrm{~s}^{-1}$ from $88^{\circ}$. Since the wave vector is the same, it follows that $\theta=182^{\circ}$, yielding $c=-6.4 \mathrm{~m} \mathrm{~s}^{-1}$, $\lambda=7.2 \mathrm{~km}$, and $\hat{\omega}=0.0153 \mathrm{~s}^{-1}$.

Local static conditions at flight level yield a buoyancy frequency $N=0.0164 \mathrm{~s}^{-1}$, so the waves are close to the criterion for decay $(\hat{\omega} \sim 0.9 N)$. We use a mean phase speed $\left(c=-6.2 \mathrm{~m} \mathrm{~s}^{-1}\right)$ and wavelength $(\lambda=7.2 \mathrm{~km})$ to determine the updraft velocity. Air flowing through the wave requires a transit time of $209 \mathrm{~s} \mathrm{(} 3.5 \mathrm{~min})$ to move from the warm phase to the cold phase. Assuming convection initially displaced the parcel upward by $300 \mathrm{~m}$, the average updraft velocity is $W=2.9 \mathrm{~m} \mathrm{~s}^{-1}$, with a peak velocity $W_{\max }=4.1 \mathrm{~m} \mathrm{~s}^{-1}$. If our calculations were in error such that the waves were formally evanescent (i.e., $\hat{\omega}=N$ ), a slightly shorter wavelength $(\lambda=6.6 \mathrm{~km})$ would yield the strongest vertical motions possible $\left(W=3.1 \mathrm{~m} \mathrm{~s}^{-1}\right.$ and $W_{\max }=4.4 \mathrm{~m} \mathrm{~s}^{-1}$, respectively).

\section{Appendix B}

\section{Homogeneous nucleation model}

Our model simulates the evolution of individual sulfuric acid solution particles within a parcel of clear TTL air. Consistent with measurements in the TTL (Lee et al., 2003), the size distribution of dry particles is log-normal and bimodal, with mode radii, spectral widths, and concentrations of 0.015 $\mu \mathrm{m}$ and $0.06 \mu \mathrm{m} ; 1.4$ and 1.5 ; and $2500 \mathrm{~cm}^{-3}$ and $150 \mathrm{~cm}^{-3}$, respectively. The parcel oscillates vertically with a frequency $\hat{\omega}$ and a vertical velocity amplitude $W$. Being a parcel model, environmental wind shear is ignored.

The model permits mixing at the interface between pileus and deep convective cloud. At the apex of the first cycle in the wave, it is assumed this mixing occurs instantaneously. Water and sensible heat are mixed linearly: i.e.,

$\zeta_{\text {mixture }}=(1-f) \zeta_{\text {pileus }}+f \zeta_{\text {convection }}$

where, $\zeta$ is the mixed quantity and $f$ the fraction mixed in from the convection. The model then tracks the sizes of individual particles as they adjust to near instantaneous (in the case of haze) and diffusive (in the case of ice) equilibration with the rapid temperature fluctuations induced by convection.

At equilibrium, we assume solution aerosol adjust their volume $V$ such that the activity $a_{w}$ of the curved solution droplet is equivalent to the relative humidity in surrounding air. The nucleation rate of ice embryos in solution $J\left(a_{w}, T\right)$ determines the probability $P=1-\exp (-J V \Delta t)$ an aerosol freezes in time period $\Delta t$ (Koop et al., 2000; Baker and Baker, 2004). According to this formulation, aerosol freeze when the saturation ratio with respect to ice $S_{i}$ reaches $\sim 1.6$. Large aerosol have the highest probability of freezing $\left(V \sim r^{3}\right)$, but smaller aerosol tend to have correspondingly high concentrations $\left(N_{a} \sim r^{-3}\right)$. Therefore, it is almost equally likely that aerosol of a given size will homogeneously freeze during $\Delta t$.

Once frozen, aerosol grow rapidly by vapor diffusion. This depletes the ambient vapor field and therefore $a_{w}$; further nucleation may be suppressed so that only a fraction of available aerosol become ice crystals. The assigned value of the condensation coefficient is 0.2 (Delval and Rossi, 2004). High ice crystal concentrations are favored by low $T$ and high $W$, and are only weakly related to the size distributions of the aerosol (Kärcher and Lohmann, 2002).

Acknowledgements. The authors gratefully acknowledge support from NASA Grants NAG511505 and NNG045I68G, S. Fueglistaler for discussions, E. Weinstock for measurements of water vapor, M. Kimball for drafting Fig. 10, and the contributions of the flight crew of the NASA WB-57F aircraft.

Edited by: B. Kärcher

\section{References}

Baker, M. B. and Baker, M.: A new look at homogeneous freezing of water, Geophys. Res. Lett., 31, L19102, doi:10.1029/2004GL020483, 2004.

Baumgardner, D., Jonsson, H., Dawson, W., O'Connor, D., and Newton, R.: The cloud, aerosol and precipitation spectrometer (CAPS): A new instrument for cloud investigations, Atmos. Res., 59-60, 251-264, 2002.

Comstock, J. M., Ackerman, T. P., and Mace, G. G.: Ground-based lidar and radar remote sensing of tropical cirrus clouds at Nauru Island: cloud statistics and radiative impacts, J. Geophys. Res., 107, 4714, doi:10.1029/2002JD002203, 2002.

Dean-Day, J., Chan, K. R., Bowen, S. W., Bui, T. P., Gary, B. L., and Mahoney, M. J.: Dynamics of Rocky Mountain lee waves 
observed during SUCCESS, Geophys. Res. Lett., 9, 1351-1354, 1998.

Delval, C. and Rossi, M. J.: The kinetics of condensation and evaporation of $\mathrm{H}_{2} \mathrm{O}$ from pure ice in the range 173-223 K: a quartz crystal microbalance study, Phys. Chem. Chem. Phys., 6, 46654676, doi:10.1039/b40995h, 2004.

Dessler, A. E. and Yang, P.: The distribution of tropical thin cirrus clouds inferred from Terra MODIS data, J. Climate, 16, 12411247, 2003

Fujita, T. T.: Principle of stereoscopic height computations and their application to stratospheric cirrus over severe thunderstorms, J. Meteorol. Soc. Japan., 60, 355-368, 1982.

Garrett, T. J., Gerber, H., Baumgardner, D. G., Twohy, C. H., and Weinstock, E. M.: Small, highly reflective ice crystals in low-latitude cirrus, Geophys. Res. Lett., 30, 2132, doi:10.1029/2003GL018153, 2003.

Garrett, T. J., Heymsfield, A. J., Ridley, B. A., McGill, M. J., Baumgardner, D. G., Bui, T. P., and Webster, C. R.: Convective generation of cirrus near the tropopause, J. Geophys. Res., 109, D21203, doi:10.1029/2004JD004952, 2004.

Garrett, T. J., Navarro, B. C., Twohy, C. H., Jensen, E. J., Baumgardner, D. G., Bui, P. T., Gerber, H., Herman, R. L., Heymsfield, A. J., Lawson, P., Minnis, P., Nguyen, L., Poellot, M., Pope, S. K., Valero, F. P. J., and Weinstock, E. M.: Evolution of a Florida cirrus anvil, J. Atmos. Sci., 62, 7, 2352-2372, doi:10.1175/JAS3495.1, 2005.

Gerber, H., Takano, Y., Garrett, T. J., and Hobbs, P. V.: Nephelometer measurements of the asymmetry parameter, volume extinction coefficient, and backscatter ratio in clouds, J. Atmos. Sci., 57, 3021-3034, 2000.

Grabowski, W. W. and Clark, T. L.: Cloud-environment interface instability: Rising thermal calculations in two spatial dimensions, J. Atmos. Sci., 48, 527-546, 1991.

Grabowski, W. W. and Clark, T. L.: Cloud-environment interface instability, part II: Extension to three spatial dimensions., J. Atmos. Sci., 50, 555-573, 1993.

Hartmann, D. L., Holton, J. R., and Fu, Q.: The heat balance of the tropical tropopause, cirrus, and stratospheric dehydration, Geophys. Res. Lett., 28, 1969-1972, 2001.

Jensen, E. J., Read, W. G., Mergenthaler, J., Sandor, B. J., Pfister, L., and Tabazadeh, A.: High humidities and subvisible cirrus near the tropical tropopause, Geophys. Res. Lett., 26, 2347 2350, 1999.

Jensen, E. J., Pfister, L., Ackerman, A. S., Tabazadeh, A., and Toon, O. B.: A conceptual model of the dehydration of air due to freeze-drying by optically thin, laminar cirrus rising slowly across the tropopause, J. Geophys. Res., 106, 17 237-17 252, 2001.

Jensen, E. J., Smith, J. B., Pfister, L., Pittman, J. V., Weinstock, E. M., Sayres, D. S., Herman, R. L., Troy, R. F., Rosenlof, K., Thompson, T. L., Fridlind, A. M., Hudson, P. K., Cziczo, D. J., Heymsfield, A. J., Schmitt, C., and Wilson, J. C.: Ice supersaturations exceeding $100 \%$ at the cold tropical tropopause: implications for cirrus formation and dehydration, Atmos. Chem. Phys., 5, 851-862, 2005

Kärcher, B. and Lohmann, U.: A parameterization of cirrus cloud formation: Homogeneous freezing including effects of aerosol size, J. Geophys. Res., 107, 4698, doi:10.1029/2001JD001429, 2002.
Koop, T., Luo, B., Tsias, A., and Peter, T.: Water activity as the determinant for homogeneous ice nucleation in aqueous solutions, Nature, 406, 611-614, 2000

Kuang, Z., Toon, G. C., Wennberg, P. O., and Yung, Y. L.: Measured $\mathrm{HDO} / \mathrm{H}_{2} \mathrm{O}$ ratios across the tropical tropopause, Geophys. Res. Lett., 30, 1372, doi:10.1029/2003GL017023, 2003.

Lacaze, J.: Remarques sur les pileus, J. Rech. Atmos., 4, 487-488, 1966.

Lane, T. P., Reeder, M. J., and Clark, T. L.: Numerical modeling of gravity wave generation by deep tropical convection, J. Atmos. Sci., 58, 1249-1274, 2001.

Lee, S.-H., Wilson, J. C., Reeves, J. M., and Lafleur, B. G.: Aerosol size distributions from 4 to $2000 \mathrm{~nm}$ measured in the upper troposphere and lower stratosphere, in: European Aerosol Conference, Madrid, Spain, 2003.

Lighthill, J.: Waves in fluids, Cambridge University Press, 2001.

Lu, M., McClatchey, R. A., and Seinfeld, J. H.: Cloud halos: numerical simulation of dynamical structure and radiative impact, J. Appl. Meteorol., 41, 832-848, 2002.

Minnis, P. D. Kratz, P., Coakley Jr., J. A., King, M. D., Garber, D., Heck, P., Mayor, S., Young, D. F., and Arduini, R.: Cloud Optical Property Retrieval (Subsystem 4.3). "Clouds and the Earth's Radiant Energy System (CERES) Algorithm Theoretical Basis Document, Volume III: Cloud Analyses and Radiance Inversions (Subsystem 4)", NASA RP 1376 Vol. 3, edited by: CERES Science Team, 135-176, 1995.

Perry, K. D. and Hobbs, P. V.: Influences of isolated cumulus clouds on the humidity of their surroundings, J. Atmos. Sci., 53, 159174, 1996.

Potter, B. E. and Holton, J. R.:The role of monsoon convection in the dehydration of the lower tropical stratosphere, J. Atmos. Sci., 52, 1034-1050, 1995.

Pruppacher, H. R. and Klett, J. D.: Microphysics of Clouds and Precipitation, 2nd Rev. Edn., Kluwer Academic Publishing, Dordrecht, 1997.

Read, W. G., Wu, D. L., Waters, J. H., and Pumphrey, H. C.: A new $147-56 \mathrm{hPa}$ water vapor product from the UARS Microware Limb Sounder, J. Geophys. Res., 109, D06111, doi:10.1029/2003JD004366, 2004.

Rosenlof, K. H.: How water enters the stratosphere, Science, 302, 1691-1692, 2003.

Roskovensky, J., Liou, K., Garrett, T. J., and Baumgardner, D. G.: Simultaneous Retrieval of Aerosol and Thin Cirrus Optical Depths using MODIS Airborne Simulator Data during CRYSTAL-FACE and CLAMS, Geophys. Res. Lett., 31, L18110, doi:10.1029/2004GL020457, 2004.

Sandor, B. J., Jensen, E. J., Stone, E. M., Read, W. G., Waters, J. W., and Mergenthaler, J. L.: Upper tropospheric humidity and thin cirrus, Geophys. Res. Lett., 27, 2645-2648, 2000.

Scorer, R.: Clouds of the World, Stackpole Books, 1972.

Scott, S., Bui, T. P., Chan, K. R., and Bowen, S. W.: The meteorological measurement system on the NASA ER-2 aircraft, J Atmos. Ocean. Technol., 7, 525-540, 1990.

Setvák, M., Rabin, R. M., Doswell III, C. A., and Levizzani, V.: Satellite observations of convective storm tops in the 1.6, 3.7 and $3.9 \mu \mathrm{m}$ spectral bands, Atmos. Res., 67-68, 607-627, 2003.

Sherwood, S. C. and Dessler, A. E.: On the control of stratospheric humidity, Geophys. Res. Lett., 27, 2513-2516, 2000.

Sherwood, S. C., Chae, J.-H., Minnis, P., and McGill, M.: Underes- 
timation of deep convective cloud tops by thermal imagery, Geophys. Res. Lett., 31, L11102, doi:10.1029/2004GL019699, 2004.

Wang, P. K.: Moisture plumes above thunderstorm anvils and their contributions to cross-tropopause transport of water vapor in midlatitudes, J. Geophys. Res., 108, D4194, doi:10.1029/2002JD002581, 2003.

Webster, C. R. and Heymsfield, A. J.: Water isotope ratios D/H, ${ }^{18} \mathrm{O} /{ }^{16} \mathrm{O},{ }^{17} \mathrm{O} /{ }^{16} \mathrm{O}$ in and out of cloud map dehydration pathways, Science, 302, 1742-1745, doi:10.1126/science, 1089496, 2003.

Webster, C. R., May, R. D., Trimble, C. A., Chave, R. G., and Kendall, J.: Aircraft (ER-2) laser infrared absorption spectrometer (ALIAS) for in-situ stratospheric measurements of $\mathrm{HCl}, \mathrm{N}_{2} \mathrm{O}$, $\mathrm{CH}_{4}, \mathrm{NO}_{2}$, and $\mathrm{HNO}_{3}$, Appl. Opt., 33, 454-472, 1994.
Weinstock, E. M., Hintsa, E., Dessler, A., Oliver, J., Hazen, N., Demusz, J., Alien, N. T., Lapson, L., and Anderson, J.: New fast response photofragment fluorescence hygrometer for use on the NASA ER-2 and the Perseus remotely piloted aircraft, Rev. Sci. Instrum., 65, 3544-3554, 1994.

Wu, D. L., Read, W. G., Dessler, A. E., Sherwood, S. C., and Jiang, J. H.: UARS/MLS cloud ice measurements: implications for $\mathrm{H}_{2} \mathrm{O}$ transport near the tropopause, J. Atmos. Sci., 62, 518-530, 2005.

Yamamoto, M. K., Fumiwara, M., Horinouchi, T., Hashiguchi, H., and Fukao, S.: Kelvin-Helmholtz instability around the tropical tropopause observed with the Equatorial Atmosphere Radar, Geophys. Res. Lett., 30, 1476, doi:10.1029/2002GL016685, 2003. 